\title{
DEVELOPING SPATIAL ORIENTATION AT YOUNG VOLLEYBALL PLAYERS
}

\author{
loan Sabin SOPA ${ }^{1}$
}

\begin{abstract}
Modern volleyball game needs to develop new skills; those new abilities are spatial orientation and balance skills. Our research focused on discovering and testing balance and spatial orientation skills of 25 volleyball players from ACS Alpha Sports Team Sibiu, aged $10.22 \pm 2.49$ years. Two tests were used as research methods with initial and final evaluation, the Matorin test and the spatial orientation test. The results showed improved results from the initial to the final tests in both tests; significant differences were found in comparing right and left direction jumps. Conclusions highlighted the importance of developing spatial orientation in young volleyball players.
\end{abstract}

Key words: spatial orientation, volleyball, training, sports performance.

\section{Introduction}

Physical exercise indicates a broad idea of combining personal potential-both physical and mental-in order to achieve primary goals. Training the psychological and physical abilities is essential for success in sports. In addition, mental preparation aids in achieving athletic performance [24].

According to research papers, understanding the mechanisms of young sportive movement skills is critical because participating in motor activity represents the first step in the development of motor skills that are essential for many functional objectives, such as frequenting school programs, games, and leisure sports activity in later years of life [26].

A high-level volleyball game means the use of alternating high-intensity and lowintensity exercise (for example, sprinting and fast running or standing in a low position to receive services) [5] [8]. Highlevel performance in sports activities, the coaching staff uses tools borrowed from other fields, sometimes closed or related, sometimes very different, such as mathematics and informatics, the form and complexity are opposite, and the method is adapted in time and

\footnotetext{
1 "Lucian Blaga” University, Department of Environmental Science, Physics, Physical Education and Sport Sibiu, Romania, e-mail: sabin.sopa@ulbsibiu.ro
} 
improvements regarding their versatility and technical possibilities, they are used because of their simplicity and applicability [27].

Volleyball is a highly specialized sports discipline. Each player determines his or her own function according to their position in the game [7], and it is an alternative to high-intensity sports and relatively effortless moments during the game-movement [8]

In recent decades, high-performance sports have experienced vigorous development, and the results are made possible by attracting and applying new advanced investigative techniques in all aspects of related fields [30].

In recent years, the improvement of volleyball players' athletic ability has enabled the team to try new offensive techniques and programs. As the height of the players and vertical jumps increase, men's and women's games have become acrobatic and exciting [31].

The spatial orientation as a cognitive function is different from the perception and visual space clusters of cognitive subtypes [6], the "visual space" clusters of cognitive variability [12], the second from the Cattell-Horn-Carroll cognitive ability theory Visual cluster processing of layers [14]. This is why its research needs to perform some visual tasks.

Spatial orientation is related to visual perception. It has been found that fieldindependent people locate themselves by the position of their body, while fieldrelated people refer to the position of the visual frame [22].

Spatial ability consists of spatial perception, spatial visualization (mental rotation and manipulation of objects in two or three dimensions), and spatial orientation-awareness of one's current location and location of simple figures within complex figures [4].

Spatial orientation is an aspect of intelligence, that is, the ability to quickly and correctly perceive and mentally manipulate numbers in various dimensions from a new perspective; organize ideas according to mental pictures-visualize to understand the imaginary movement in two or three dimensions; configure and keeping the direction of change without confusion; forming and using cognitive mapscomplex environmental, psychological representations based on environmental landmarks and spatial relationships [4].

Important coordination ability is visuospatial skills [36]. This ability prevents us from getting lost and can read or construct maps of the surrounding space. It is realized and maintained by a complex set of sensorimotor control systems: sensory input from vision, proprioception, and vestibular system [18]. In order to determine this ability, individual internal components and environmental factors intervene [33].

Spatial orientation is essential to maintain the correct posture for sports and most sports activities. Three different vestibular, visual, and somatosensory systems are distinguished, which control these complex behaviors [3], [11].

Motion sensation is a kind of "muscle feeling", a way of accepting your movements and positions. Another view describes it as "a sensation mediated by nerve endings located in muscles, tendons, and joints, stimulated by body movement and tension" [19]. Reaction time provides an indirect indicator of the processing power of the central nervous system and a simple method to determine sensorimotor performance [17]. The 
reaction time is the interval between the onset of the signal (stimulus) and the onset of the motor response [23]. Exercise time is the time interval between the start and completion of the exercise. Response time is the cumulative effect of reaction time and exercise time [13].

Wilson et al. [35] It is required to consider psychomotor factors more fully in talent research and recognize that players with good psychomotor factors (for example, technical skills) are very coveted players.

\section{Materials and Methods}

\subsection{Objectives of the research}

The research objectives followed the assessment of the spatial orientation of a group of young volleyball players. The main target was to test the ability of our players to orientate themselves using specific tests and then develop this critical skill, so their volleyball level improves.

\subsection{Design of the research}

The primary method was using the Matorin test to assess the volleyball players' spatial orientation. The test consisted of two evaluation periods, the first was conducted in April 2019, and the second the final evaluation was taken in September 2019, after six months of developing spatial orientation skills.

\subsection{Participants of the research}

The research took place at the ACS Alpha Sports Team from Sibiu, between April 2019 and September 2019, having as participants at the research 25 female players with ages between $10.22 \pm 2.49$ years; height between $1.45 \pm 10.42 \mathrm{~cm}$; weight between $32.62 \pm 10.15 \mathrm{~kg}$; and experience of $1.2 \pm 2.4$ years played; with a four weekly training frequency, who practice two to three times a week for at least two years, and have no musculoskeletal leg injuries. All participants were tested in the middle of the season. However, during the week of data collection, the athletes did not conduct volleyball-specific training. All procedures are carried out in the afternoon, and athletes are instructed to eat and normally drink before the test and avoid heavy eating.

According to National Health Commission Resolution No. 466/2012 and the Declaration of Helsinki, the Institutional Ethics Committee approved the protocol ("Lucian Blaga" University Ethics Committee), and all participants signed an informed consent form. Before participating in the study, participants were informed of the procedures that gave them the right to withdraw. All the volleyball players were minors, so we obtained the legal guardian's written agreement.

\subsection{The Matorin test}

The Matorin test consists of jumping and spinning in the air as much as possible and registering the degrees that the subject succeeds in spinning. The research subjects had to try in each direction ( 2 tries spinning in the left direction, two tries spinning in the right direction).

The test is to draw a $100 / 70 \mathrm{~cm}$ cross on the ground, in a north-south direction; the subject stands with the soles of each side of this line. The subject must not lose balance during the test and land at the same place and position as the starting point [16]. 
The purpose of this test is to highlight the overall coordination of the subject. The test itself involves the subject jumping around its longitudinal axis. This theme aims to achieve the widest rotation. Rotation is measured in degrees.

The subject was asked to jump twice to the right and twice to the left and eventually jumped best on each side. In addition, if the subject loses balance or falls outside the landing zone, the jump is not verified. The meaning of the first jump, right or left, is up to each subject to decide. Four pieces of thin cardboard were used for this test, but they were glued together. The size of a board is 100 $\mathrm{cm} \times 70 \mathrm{~cm}$. The surface is graded to measure the jump amplitude as accurately as possible. The surface of the cardboard is fixed with resistant tape, which will not leave a rotational movement after jumping.

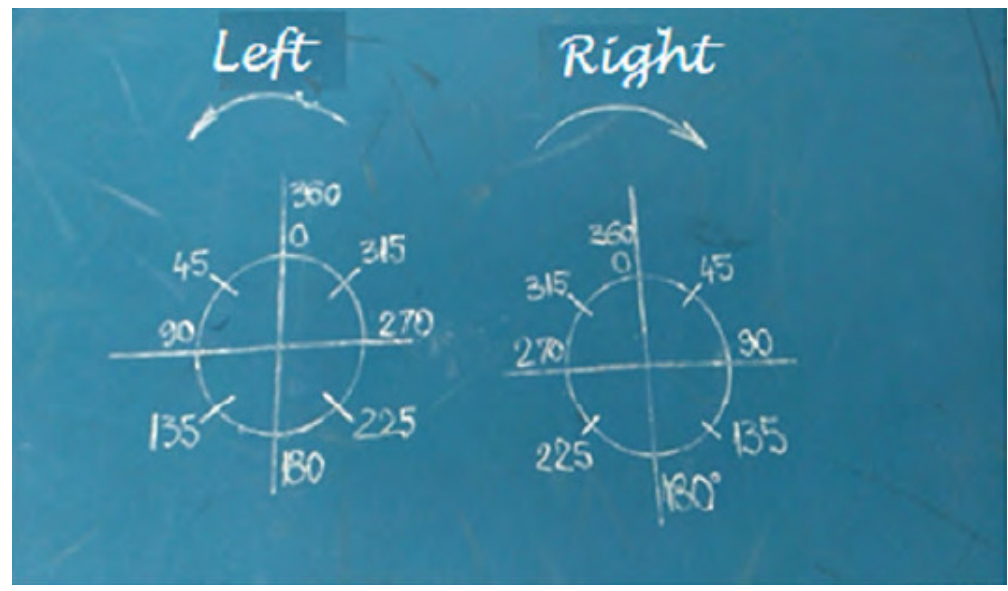

Fig. 1. Measuring scale for the Matorin test [16]

\subsection{Spatial perception and dynamic balance test}

This test is used to investigate proprioception and spatial orientation and to determine coordination skills and dynamic balance. The material used for the test is minimal, consisting of tape rolls, measuring objects, and roulette. The subjects' task is to move 12 meters straight and stop when they feel they have reached their destination. The start and endpoints are clearly marked; they are connected by a straight line of tape extending to the hall floor. The displacement of the subjects was carried out without the support of a vision analyzer.

They were wearing ski goggles, which had been modified by applying black foil on the viewfinder to prevent light from penetrating the glasses and changing the test results. Positioned at the starting point, the subjects were asked to imagine the route before wearing glasses and focus on the endpoint.

There is no start command; the subjects start the test at a specific time of their choice. In order to improve the accuracy of the test, the subject is not subject to interference from other sounds or other factors. The test was conducted in a stadium measuring 38 meters in length, 18 meters in width, and 7.5 meters in height. 
When the subject stopped, he was asked to stay in place to use a roulette to take measurements. Two parameters "+", "-", "12m" and left-right deviation are recorded. All values obtained through this test are expressed in centimeters.

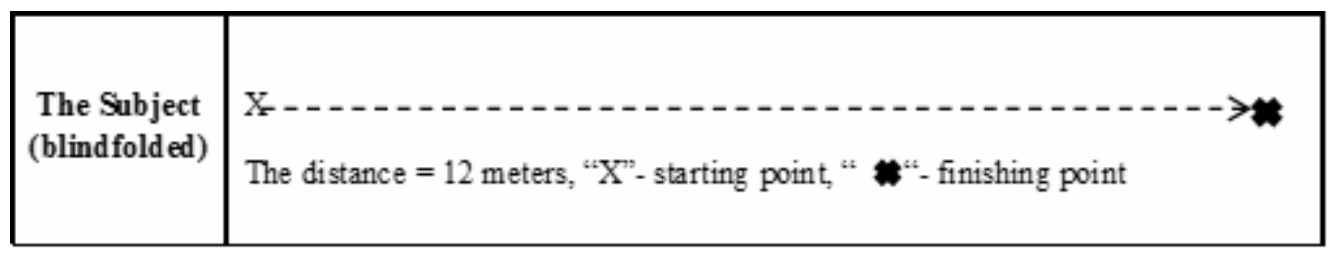

Fig. 2. The representation of the spatial perception test [25]

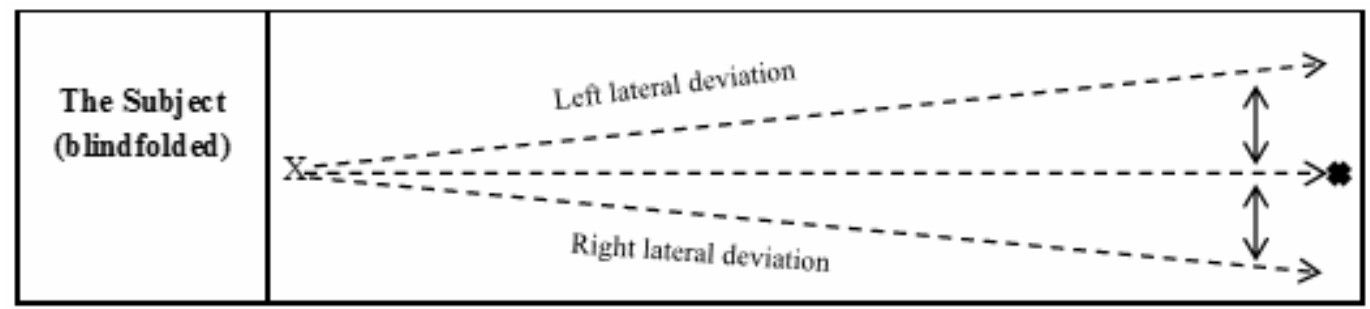

Fig. 3. The representation of lateral deviation of the spatial perception test [25]

\section{Results of the Research}

The research had two tests as main research methods: the Matorin test (Fig. 1) and the Spatial orientation test (Figure 2 and 3), both had two test sessions the first was the initial test that was taken in February 2020 (Matorin test Table 1 and Figure 1), where the initial parameters of spatial orientation were registered, the second assessment was the final test taken in April 2020 (Matorin test Table 2 and Figure 2). Both results were grouped in tables and then statistically compared to analyze if any statistically significant difference could be observed.

Initial testing of the dynamic balance with the Matorin test

Table 1

\begin{tabular}{|c|c|c|c|c|}
\hline \multirow{3}{*}{ Initial test } & \multicolumn{4}{|c|}{ Subjects of the research $(n=25)$} \\
\hline & \multicolumn{2}{|c|}{ Matorin test (jump right) } & \multicolumn{2}{|c|}{ Matorin test (jump left) } \\
\hline & First jump & Second jump & First jump & Second jump \\
\hline Average of the group & 340.20 & 345.15 & 350.65 & 355.45 \\
\hline Std. deviation & 0.12 & 0.56 & 0.45 & 0.55 \\
\hline Max value & 360 & 360 & 355 & 360 \\
\hline Min value & 320 & 330 & 330 & 365 \\
\hline Skewness index & 0.32 & 1.25 & 1.25 & 1.75 \\
\hline Kurtosis index & -0.25 & -0.33 & -0.45 & -0.30 \\
\hline$P$ value (between right and left values) & 0.233 & 0.045 & 0.228 & 0.125 \\
\hline $\begin{array}{l}\text { P value (between first and second } \\
\text { jumps) }\end{array}$ & 0.037 & 0.875 & 0.033 & 0.224 \\
\hline
\end{tabular}




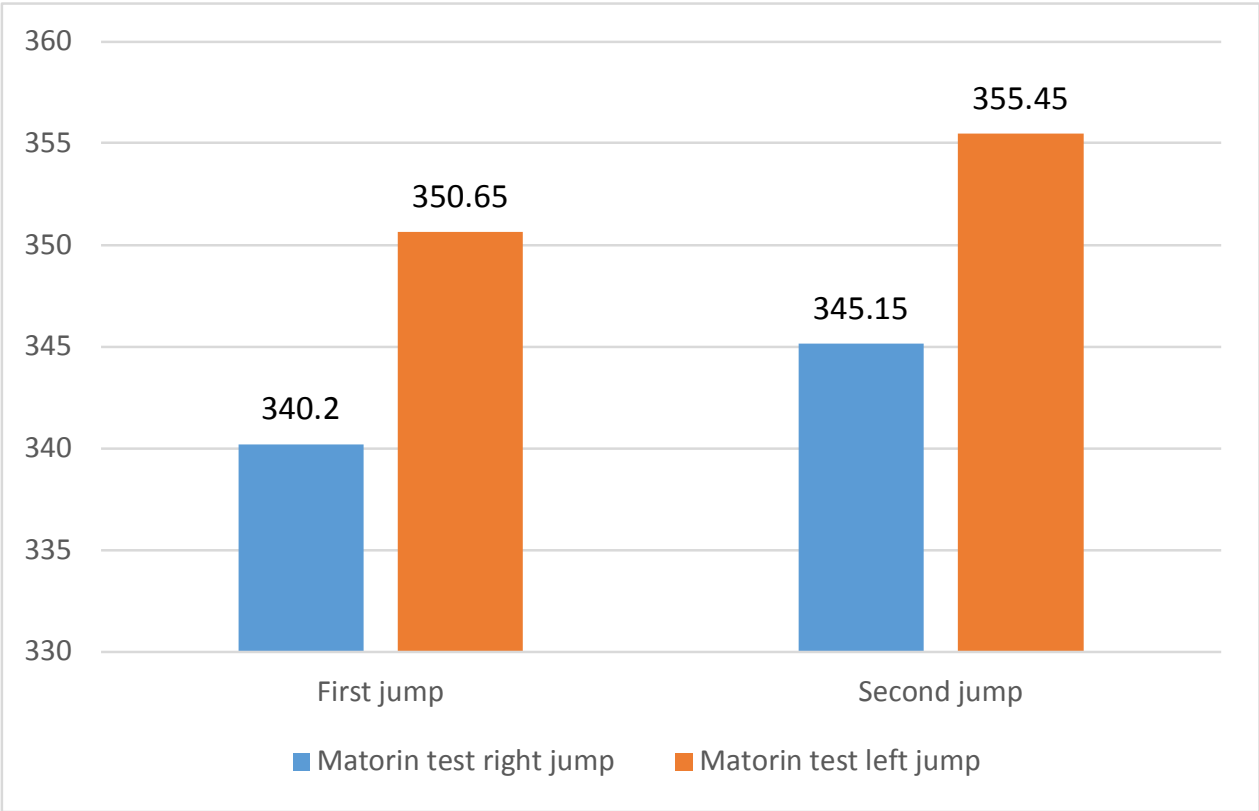

Fig. 4. Matorin test initial assessment

The results of the initial test at the Matorin test (Table 1 and Fig. 4) showed that the volleyball group obtained good results, better at the second jump in both directions (right and left direction) with a statistically significant difference only at the right direction jump compared with the left direction jump $(p=0.045)$, and also at the first jump of every direction jump (right first jump $p=0.037$ and left first jump $p=0.033$ ).

Final testing of the dynamic balance with the Matorin test

Table 2

\begin{tabular}{l|cc|cc}
\hline \multirow{1}{*}{ Final test } & \multicolumn{4}{c}{ Subjects of the research (n=25) } \\
\cline { 2 - 5 } & \multicolumn{2}{c}{$\begin{array}{c}\text { Matorin test (jump right) } \\
\text { First jump }\end{array}$} & Second jump & Matorin test (jump left) \\
& 356.45 & $\mathbf{3 6 5 . 2 2}$ & 358.33 & $\mathbf{3 6 3 . 6 2}$ \\
\hline Average of the group & 14.23 & 3.15 & 22.65 & 2.05 \\
Std. deviation & 360 & 365 & 362 & 370 \\
Max value & 345 & 345 & 353 & 355 \\
Min value & 1.35 & 0.75 & 0.55 & 2.25 \\
Skewness index & -0.45 & -0.15 & -1.25 & -0.67 \\
Kurtosis index & 0.114 & 0.865 & $\mathbf{0 . 0 3 3}$ & 0.044 \\
P value (right and left values) & 0.298 & 0.625 & 0.446 & $\mathbf{0 . 0 2 5}$ \\
P value (first and second & & & & \\
jumps) & & & & \\
\hline
\end{tabular}




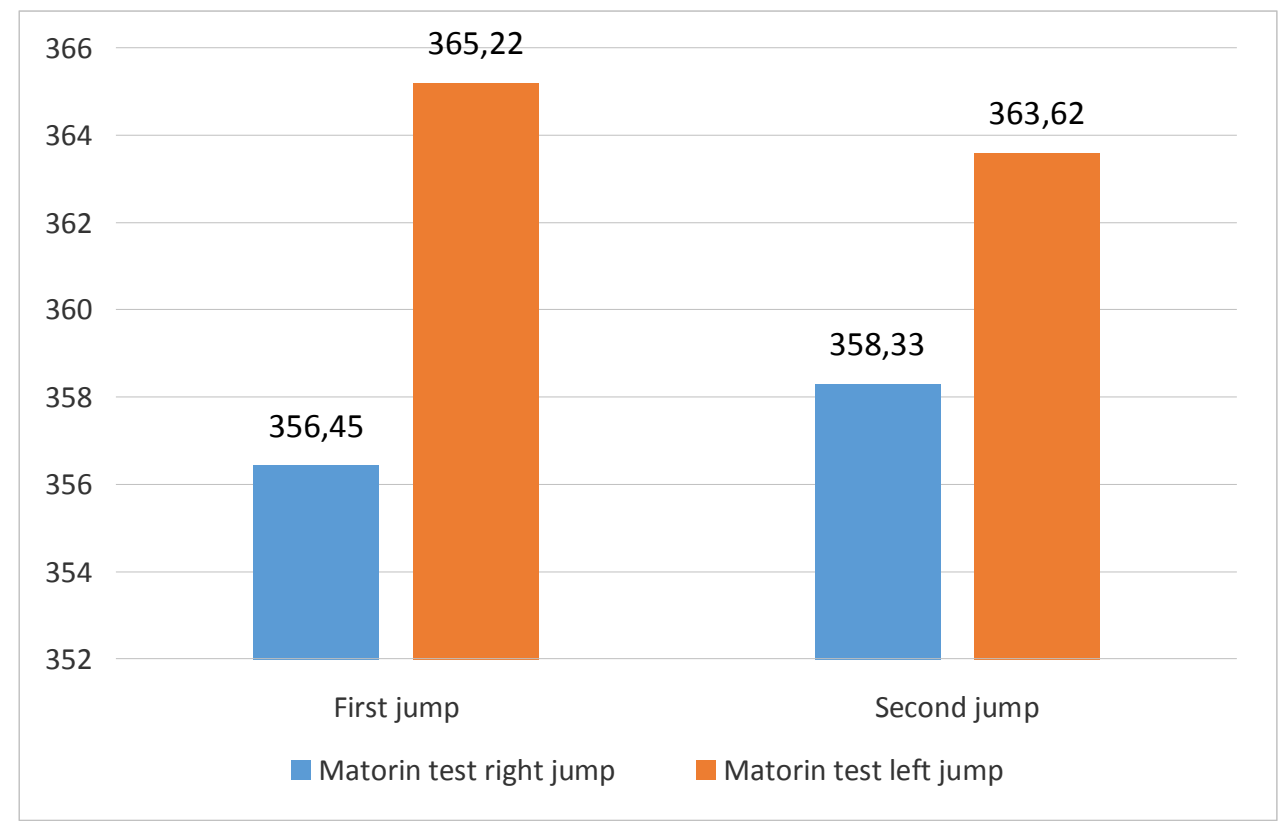

Fig. 5. Matorin test final assessment

At the second assessment, the final testing, the Matorin test, registered better results in both jumping directions (right and left). Significant statistical difference was found at the left first jump compared with the first right jump ( $p=0.033)$ and between the first and second jump at the second and first jump at the left direction $(p=0.025)$.
The second assessment used was the spatial orientation test (Fig. 2 and 3) that also had two evaluations (initial and final) at the same time as the first test (Matorin test). The presented results are presented below (Tables 3 and 4 and in Figures 6 and 7).

Initial testing of the spatial orientation skill

Table 3

\begin{tabular}{|c|c|c|c|c|}
\hline \multirow[b]{2}{*}{ Initial test } & \multicolumn{4}{|c|}{ Spatial orientation test } \\
\hline & $\begin{array}{l}\text { Deviation Left } \\
\text { (cm) }\end{array}$ & $\begin{array}{l}\text { Deviation Right } \\
\text { (cm) }\end{array}$ & $\begin{array}{l}\text { Deviation + } \\
(\mathrm{cm})\end{array}$ & $\begin{array}{c}\text { Deviation - } \\
(\mathrm{cm})\end{array}$ \\
\hline Average of the group & 53.04 & 105.22 & 65.22 & 33.56 \\
\hline Std. deviation & 83.69 & 133.25 & 77.03 & 82.18 \\
\hline Max value & 356.00 & 367.00 & 255.00 & 310.00 \\
\hline Min value & 0.00 & 0.00 & 0.00 & 0.00 \\
\hline Skewness index & 3.56 & 2.91 & 1.14 & 4.22 \\
\hline Kurtosis index & 3.22 & 1.22 & 2.28 & 24.25 \\
\hline$P$ value & \multicolumn{2}{|c|}{0.343} & \multicolumn{2}{|c|}{0.521} \\
\hline
\end{tabular}


Final testing of the spatial orientation skill

Table 4

\begin{tabular}{lcccc}
\hline \multirow{2}{*}{ Final test } & \multicolumn{4}{c}{ Spatial orientation test } \\
\cline { 2 - 5 } & $\begin{array}{c}\text { Deviation Left } \\
(\mathrm{cm})\end{array}$ & $\begin{array}{c}\text { Deviation Right } \\
(\mathrm{cm})\end{array}$ & $\begin{array}{c}\text { Deviation }+ \\
(\mathrm{cm})\end{array}$ & $\begin{array}{c}\text { Deviation - } \\
(\mathrm{cm})\end{array}$ \\
\hline Average of the group & 43.96 & 94.58 & 56.46 & 24.15 \\
Std. deviation & 77.69 & 123.08 & 69.83 & 59.28 \\
Max value & 304.00 & 325.00 & 205.00 & 290.00 \\
Min value & 0.00 & 0.00 & 0.00 & 0.00 \\
Skewness index & 2.22 & 0.88 & 1.14 & 3.96 \\
Kurtosis index & 4.68 & -0.93 & 0.17 & 17.34 \\
P value & & 0.041 & & 0.039 \\
\hline
\end{tabular}

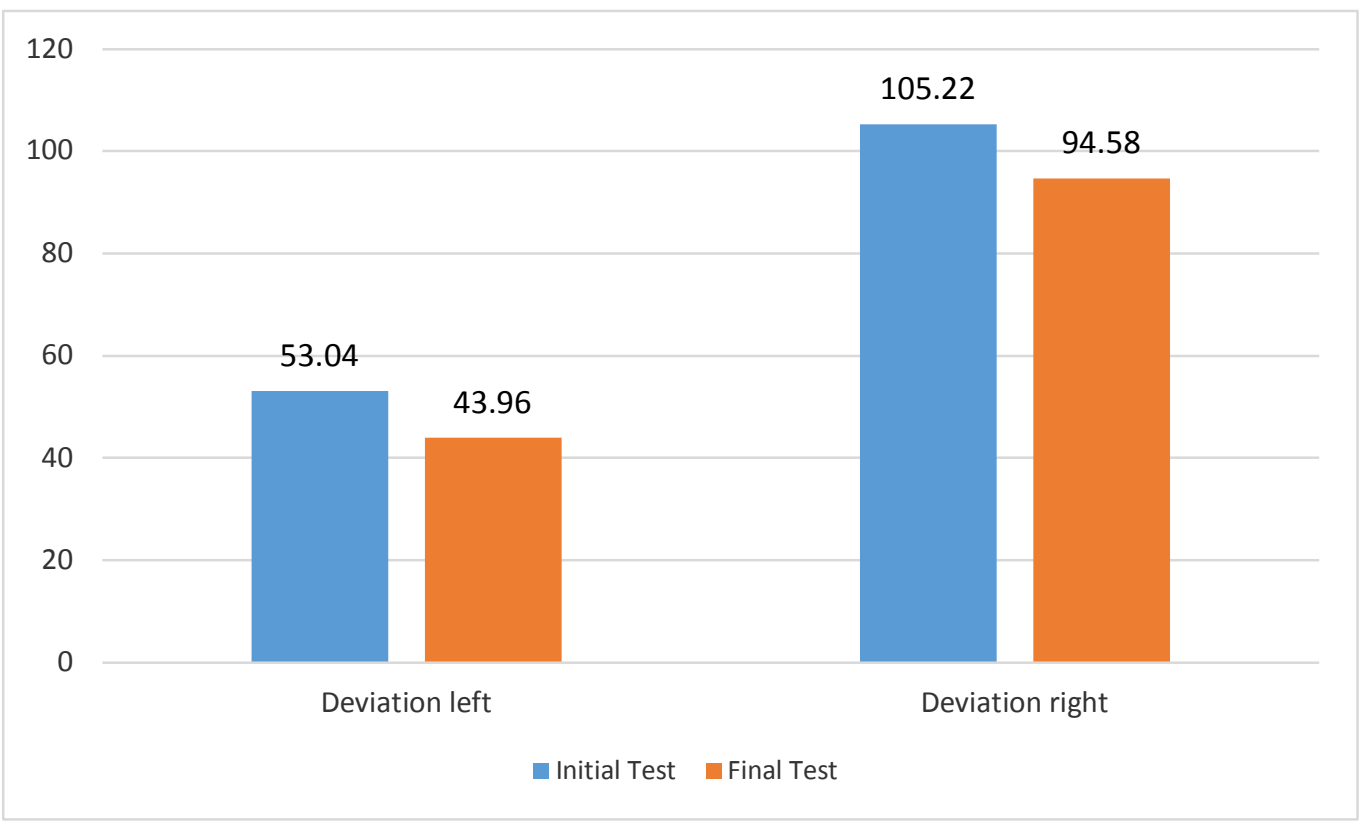

Fig. 6. Graphical representation of the spatial orientation test

The results at the spatial orientation test (Tables 3 and 4 and Fig. 6) highlighted the progress that the volleyball players made through training. At the initial testing, we also had an average deviation to the left of $53.04 \mathrm{~cm}$ compared with $43.96 \mathrm{~cm}$ at the final evaluation. The deviation to the right registered a value of $105.22 \mathrm{~cm}$ compared with the final assessment, where we obtained $94.58 \mathrm{~cm}$. The results at the final testing (right and left) were statistically significant, with a value of $\mathrm{p}=0.041$ and 0.039 .

\section{Discussions}

Volleyball has a variety of game actions, from the simplest to the most complicated. This requires players to continue training and perseverance, and the coach has to carry out the teachinglearning process sequence in stages, making this game a little more subtle [28]. 
Volleyball game can be learned with high efficiency from young age even in high school lower cycle of study [1] [2], [21], [32].

Spatial positioning skills are an essential ability in modern volleyball and are used in various technical elements. Some research papers have found that men are better than women in spatial abilities (such as mental rotation) [4].

Other research results support the hypothesis that athletes have no gender differences in spatial orientation, which improves with more ample exercise experience and training. The difference in spatial direction may be partly due to the different preparation and performance levels of national and regional competitors. Research has found that long-term sports practice is related to better spatial positioning, such as countries with more extended (but not significantly more) sports experience $(M=9.8$ years; $S D=5$ years) than regional competitors. Grade athletes have done it $(\mathrm{M}=8.6$ years; $\mathrm{SD}=10$ years) [24].

Using the Matorin test (Fig. 1), we evaluated the spatial orientation level of our players. The results showed good performances of our players, finding significant statistical values both at the initial test (Table 1 and Figure 4) comparing right and left direction jump $(p=0.045)$ and also at the first jump of every direction jump (right first jump $p=0.037$ and left first jump $p=0.033$ ). Also, statistically significant values were found in the final evaluation (Table 2, Figure 5) at the left first jump compared with the first right jump $(p=0.033)$, and also between the first and second jump at the second and first jump at the left direction $(p=0.025)$.

Other scientific research found similar results of 319.04 degrees at male and
318.20 degrees at female gender to the right and 306.17 degrees at male and 304.07 at the female gender to the left side [18] or 315 degrees average value to the right and 305 degrees to the left [9]. In other studies, regarding performance sports activities, for example at volleyball, players with ages $9-12$ years registered an average of 270.98 average results to the left and right at the Matorin test [34], or in other research was found similar final results at a basketball sample with a result of 300.42 to the right and 277.7 to the left [15]. Also, in a study regarding football players between 10 and 12 years old, a final result of 311 degrees results to the left and 311.5 degrees to the right at the Matorin test [16].

At the second spatial orientation test (Fig. 2 and 3), we found statistically significant differences at the final evaluation (Table 4 and Figure 6) between the right and left deviation with a value of $p=0.041$ and 0.039 .

Modern volleyball is characterized by fast speed and many movements. Through continuous operation improvement, the shot is getting higher and higher, the combination of offense and defense is creative, and the service is more substantial and efficient because serving is the first element for winning one point [29].

\section{Conclusions}

The results highlighted the importance of developing spatial orientation skills in volleyball games and finding the level using specific orientation tests.

The results found in the investigation were close to other scientific discoveries found in this domain, showing that our volleyball players are well prepared. 


\section{References}

1. Ardelean M., Neagu N., Szabo, D. A.: Pedagogical considerations regarding the structure of high school lower cycle syllabuses, for the "Theoretical Sports Training" school subject (Note I). In: Health, Sports \& Rehabilitation Medicine, 2020, 21(4), p. 256-259. https://doi.org/10.26659/pm3.2020.2 1.4.256

2. Ardelean M., Neagu N., Szabo, D. A.: Pedagogical considerations regarding the structure of high school upper cycle syllabuses, for the "Theoretical Sports Training" school subject (Note II). Health, Sports \& Rehabilitation Medicine, Vol. 22, 2021, (1), p. 36-39. https://doi.org/10.26659/pm3.2021.2 2.1.36

3. Barra, J., Marquer, A., Joassin, R., Raymond, C., Chauvineau, V., Pérennou, D.: Human use internal models to construct and update a sense of verticality. In: Brain a Journal of Neurology, Vol. 133, Issue 12, 2010, p. 3552-3563. DOI:10.1093/brain/ awq311

4. Bergqvist, E.: Spatial orientation \& imagery. What are the gender differences in spatial orientation and mental imaging when navigating a virtual environment with only auditory cues? A Master degree thesis. Skövde, Sweden: University of Skövde, 2015.

5. Calleja-Gonzalez, J., Mielgo-Ayuso, J., Sanchez-Urena, B., Ostojic, S. M., Terrados, N.: Recovery in volleyball. In: The Journal of Sports Medicine and Physical Fitness. Vol. 59, Issue 6, 2019, p. 982-93. DOI: 10.23736/S00224707.18.08929-62.

6. Cappa, A., Ciccarelli, N., Baldonero, E., Martelli, M., Silveri, M. C.: Posterior
AD-Type pathology: Cognitive subtypes emerging from a cluster analysis. In: Behavioural Neurology, 2014, Article ID 259358. doi:10.1155/2014/259358.

7. D’Anastasio, R., Milivojevic, A., Cilli, J., Icaro, I., Viciano, J.: Anthropometric profiles and somatotypes of female volleyball and beach volleyball players. In: International Journal of Morphology, Vol. 37, Issue 4, 2019, p. 1480-1485.

8. Gabbett, T., Georgieff, B.: Physiological and anthropometric characteristics of Australian junior national, state, and novice volleyball players. In: Journal of Strength and Conditioning Research, Vol. 21, 2007, p. 902-908. DOI: 10.1519/R-20616.1.

9. Găvojdea, A.M.: Study regarding balance in 9-10 years old gymnasts. In: The European Proceedings of Social \& Behavioural Sciences EpSBS, Future Academy, Vol. 11, Issue 1, 2015, p. 218-225. DOI:http://dx.doi.org/10.15405/epsbs .2016.06.30.

10. González, D. L.: An Exactly Soluble Model for Volleyball Matches Scores. In: Revista Brasileira de Ensino de Física, Vol. 35, Issue 2, 2013, p. 1-8. DOI: 10.1590/S1806-11172013000200002.

11. Joassin, R., Bonniaud, V., Barra, J., Marquer, A., Perennou, D.: Somaesthetic perception of the vertical in spinal cord injured patients: A clinical study. In: Annals of Physical and Rehabilitation Medicine, Vol. 53, Issue 9, 2010, p. 568-574. DOI: 10.1016/j.rehab.2010.07.005.

12. Lewandowski, K.E., Sperry, S.H., Cohen, B.M., Öngür, D.: Cognitive variability in psychotic disorders: an exploratory cross-diagnostic cluster 
analysis. In: Psychological Medicine, Vol. 44, Issue 15, 2014, p. 3239-48. DOI: $10.1017 /$ S0033291714000774.

13. Mannie, K.: Scholastic Inc, FindArticles.com: In: Coach and Athletic director; 2011. Feb 23, Improving Quickness Response time. http://findarticles.com/p/articles/mi m0FIH/is_9_70/ai_n18611822/

14. McGrew, K.: Editorial: $\mathrm{CHC}$ theory and the human cognitive abilities project: Standing on the shoulders of the giants of psychometric intelligence research. In: Intelligence, Vol. 37, Issue 1, 2009, p. 1-10.

15. Moldovan, E., Enoiu, R.: Study regarding psychomotricity and its role in the sporting preparation process of the basketball player. In: Bulletin of the Transilvania University of Braşov, Series VIII, Vol. 4, Issue 53, 2011, p.137-146. Retrieved from: http://webbut.unitbv.ro/BU2011/Seri es\%20VIII/BULETIN\%20VIII/S_05_Mol dovan_Elena-sport.pdf

16. Monea, D., Prodan, R., Ștefănescu, H., Grosu, V.: Skill development using football specific methods and tests for 10-12 year old children. In: Studia UBB Educatio Artis Gymnasium. 2017; Vol. 62, Issue 1, 2017, p. 25-39. DOI:10.24193/subbeag.62(2).12.

17. Namita, S., Rajan, D. P., Shenvi, D. N.: Effect of shift working in reaction time in hospital employees. In: Indian Journal of Physiology and Pharmacology, Vol. 54, 2010, p. 289293. PMID: 21409868. Retrieved from: https://www.yumpu.com/en/docume nt/read/22591773/effect-of-shiftworking-on-reaction-time-in-hospitalemployees

18. Notarnicola, A., Maccagnano, G., Pesce, V., Tafuri, S., Novielli, G.,
Moretti, B.: Visual- spatial capacity: gender and sport differences in young volleyball and tennis athletes and nonathletes. BMC Research Notes, Vol. 7, Issue 57, 2014, p. 1-7. https://doi.org/ 10.1186/1756-0500-7-57

19. Paterson, M.: Movement for Movement's Sake? On the Relationship between Kinaesthesia and Aesthetics. In: Essays in Philosophy, Vol. 13, Issue 2, 2012, p. 471-497. DOI: http://dx.doi.org/ 10.7710/1526-0569.1433

20. Păcuraru, A., Preda, C., Ciocoiu, L.: Comparative study on the coordinative ability of primary school. In: Bulletin of the Transilvania University of Braşov, Vol. 3, Issue 52, 2010, p. 125-128. Retrieved from: http://webbut. unitbv.ro/BU2010/Series\%20VIII/BULE TIN\%20VIII\%20PDF/SPORT\%20STUDIE S/12_Pacuraru\%20A.pdf

21. Popa, C. O., Schenk, A., Rus, A., Szasz, S., Suciu, N., Szabo, D.A., Cojocaru, C.: The Role of Acceptance and Planning in Stress Management for Medical Students. In: Acta Marisiensis - Seria Medica, 2020, 66(3), p.101-105.

22. Schuster, B.: Gestalt Perception Test. Release 22.00. 2003; Mödling, Austria: Dr.G.Schuhfried Ges.m.b.H.

23. Senel, O., Eroglu, H.: Correlation between reaction time and speed in elite soccer players. In: Journal of Exercise Science Fitness, Vol. 4, Issue 2, 2006, p. 126-130. Retrieved from: http://citeseerx.ist.psu.edu/viewdoc/do wnload?doi=10.1.1.561.2453\&rep=rep1 \&type=pdf

24. Stoyanova, S., Ivantchev, N., Petrova, $\mathrm{K}$.: Spatial orientation in sportsmen. In: European Scientific Journal, Vol. 12, Issue 24, 2016, p. 88-97. DOI: 10.19044/esj.2016.v12n24p88 
25. Szabo, D. A., Neagu, N., Ardelean, M., Sopa, I. S.: Psychomotor evaluation of sportive and non-sportive children. In: Discobolul-Physical Education, Sport and Kinetotherapy Journal, Vol. 20, Issue 1, 2020, p. 120-127.

26. Szabo, D. A., Neagu, N., Teodorescu, S., Pomohaci, M., Sopa, I. S.: Does smart electronic device influence the body deficiencies development at kids who practice swimming? In: International Journal of Applied Exercise Physiology, Vol. 8, Issue 2.1, 2019, p. 845-851. DOI: 10.30472/ijaep.v8i2.1.566.

27. Szabo, D.A., Neagu, N., Teodorescu, S., Pomohaci, M., Sopa, I.S.: Modalities of exploitation the information provided by the Click \& Scout statistical program in preparing volleyball attack players. In: International Journal of Applied Exercise Physiology, Vol. 8, Issue 2.1., 2019, p. 852-859. DOI: 10.30472/ijaep.v8i2.1.566.

28. Szabo, D. A.: Modalities of using the information provided by the statistical program Click \& Scout for improving the outside hitters' efficiency in volleyball game. In: The European Proceedings of Social \& Behavioral Science EpSBS, Future Academy, Vol. XI, Issue 47, 2016, p. 341-347. http://dx.doi.org/10.15405/epsbs(235 7-1330).2016.6.

29. Szabo, D. A.: Study on improving the service unforced errors in volleyball game by using a statistical software. In: International Scientific Conference eLearning and Software for Education eLSE, Vol. 3, 2015, p. 320-326. DOI: 10.12753/2066-026X-15-229.

30. Szabo, D.A., Magdas, L.: Increasing the defensive efficiency in volleyball using the statistical program Click \& Scout. Publishing House of Universitatea
Naţională de Apărare "Carol I", Vol. 4, 2014, p. 223-228.

31. Szabo, D. A., Magdas, L: Improving the offensive efficiency in volleyball game by using a specific statistics software. In: Discobolul-Physical Education, Sport and Kinetotherapy Journal, Vol. X, Issue 4, 2014, p. 14-17.

32. Tulbure, R.E., Neagu, N., Szabo, D.A.: Comparative study on the development of the motor skill (strength) through the circuit method versus dynamic games in physical education classes. In: Health, Sports \& Rehabilitation Medicine, 2020, 21(4), p. 223-230. https://doi.org/ 10.26659/pm3.2020.21.4.223

33. Vona, G., Massidda, M., Cireddu, M. I., Calò, C.M.: Genetics and sport performance. In: Italian Journal of Sport Science, Vol. 12, 2005. p. 105-115.

34. Wesselly, T., Răchită, I., GrigoroiuNorocel, C.: Study regarding the development of debutant volleyball players' coordinative capacity. In: Marathon Journal, 2015; Vol. 7, Issue 2, 2015, p. 297-301. Retrieved from: http://marathon.ase.ro/pdf/vol7/vol2/1 8\%20Teodora\%20Wesselly.pdf

35. Wilson, R.S., James, R.S., David, G., Hermann, E., Morgan, O.J., Niehaus, A.C.: Multivariate analyses of individual variation in soccer skill as a tool for talent identification and development: utilising evolutionary theory in sports science. In: Journal of Sports Sciences, Vol. 34, Issue 21, 2016, p. 2074-86. DOI: 10.1080/02640414.2016.1151544

36. Wolbers, T., Hegarty, M.: What determines our navigational abilities? In: Trends in Cognitive Science, Vol. 14, Issue 3, 2010, p. 138-146. DOI: 10.1016/j.tics.2010.01.001. 